mediastudies.press • Social Media \& the Self: An Open Reader

\title{
Attention Is Not a \\ Resource but a Way of \\ Being Alive to the World
}

Dan Nixon

Published on: Dec 07, 2018

License: Creative Commons Attribution-NoDerivatives 4.0 International License (CC-BY-

ND 4.0). 
'WE ARE DROWNING in information, while starving for wisdom.' Those were the words of the American biologist E O Wilson at the turn of the century. Fastforward to the smartphone era, and it's easy to believe that our mental lives are now more fragmentary and scattered than ever. The 'attention economy' is a phrase that's often used to make sense of what's going on: it puts our attention as a limited resource at the centre of the informational ecosystem, with our various alerts and notifications locked in a constant battle to capture it.

That's a helpful narrative in a world of information overload, and one in which our devices and apps are intentionally designed to get us hooked. Moreover, besides our own mental wellbeing, the attention economy offers a way of looking at some important social problems: from the worrying declines in measures of empathy through to the 'weaponisation' of social media.

The problem, though, is that this narrative assumes a certain kind of attention. An economy, after all, deals with how to allocate resources efficiently in the service of specific objectives (such as maximising profit). Talk of the attention economy relies on the notion of attention-as-resource: our attention is to be applied in the service of some goal, which social media and other ills are bent on diverting us from. Our attention, when we fail to put it to use for our own objectives, becomes a tool to be used and exploited by others.

However, conceiving of attention as a resource misses the fact that attention is not just useful. It's more fundamental than that: attention is what joins us with the outside world. 'Instrumentally' attending is important, sure. But we also have the capacity to attend in a more 'exploratory' way: to be truly open to whatever we find before us, without any particular agenda.

During a recent trip to Japan, for example, I found myself with a few unplanned hours to spend in Tokyo. Stepping out into the busy district of Shibuya, I wandered aimlessly amid the neon signs and crowds of people. My senses met the wall of smoke and the cacophony of sound as I passed through a busy pachinko parlour. For the entire morning, my attention was in 'exploratory' mode. That stood in contrast to, say, when I had to focus on navigating the metro system later that day.

Treating attention as a resource, as implied by the attention-economy narrative, tells us only half of the overall story - specifically, the left half. According to the British psychiatrist and philosopher Iain McGilchrist, the brain's left and 
right hemispheres 'deliver' the world to us in two fundamentally different ways. An instrumental mode of attention, McGilchrist contends, is the mainstay of the brain's left hemisphere, which tends to divide up whatever it's presented with into component parts: to analyse and categorise things so that it can utilise them towards some ends.

By contrast, the brain's right hemisphere naturally adopts an exploratory mode of attending: a more embodied awareness, one that is open to whatever makes itself present before us, in all its fullness. This mode of attending comes into play, for instance, when we pay attention to other people, to the natural world and to works of art. None of those fare too well if we attend to them as a means to an end. And it is this mode of paying attention, McGilchrist argues, that offers us the broadest possible experience of the world.

So, as well as attention-as-resource, it's important that we retain a clear sense of attention-as-experience. I believe that's what the American philosopher William James had in mind in 1890 when he wrote that 'what we attend to is reality': the simple but profound idea that what we pay attention to, and how we pay attention, shapes our reality, moment to moment, day to day, and so on.

It is also the exploratory mode of attention that can connect us to our deepest sense of purpose. Just note how many noninstrumental forms of attention practice lie at the heart of many spiritual traditions. In Awareness Bound and Unbound (2009), the American Zen teacher David Loy characterises an unenlightened existence (samsara) as simply the state in which one's attention becomes 'trapped' as it grasps from one thing to another, always looking for the next thing to latch on to. Nirvana, for Loy, is simply a free and open attention that is completely liberated from such fixations. Meanwhile, Simone Weil, the French Christian mystic, saw prayer as attention 'in its pure form'; she wrote that the 'authentic and pure' values in the activity of a human being, such as truth, beauty and goodness, all result from a particular application of full attention.

The problem, then, is twofold. First, the deluge of stimuli competing to grab our attention almost certainly inclines us towards instant gratification. This crowds out space for the exploratory mode of attention. When I get to the bus stop now, I automatically reach for my phone, rather than stare into space; my fellow commuters (when I do raise my head) seem to be doing the same thing. Second, on top of this, an attention-economy narrative, for all its usefulness, reinforces a conception of attentionas-a-resource, rather than attention-as-experience. 
At one extreme, we can imagine a scenario in which we gradually lose touch with attention-as-experience altogether. Attention becomes solely a thing to utilise, a means of getting things done, something from which value can be extracted. This scenario entails, perhaps, the sort of disembodied, inhuman dystopia that the American cultural critic Jonathan Beller talks about in his essay 'Paying Attention' (2006) when he describes a world in which 'humanity has become its own ghost'.

While such an outcome is extreme, there are hints that modern psyches are moving in this direction. One study found, for instance, that most men chose to receive an electric shock rather than be left to their own devices: when, in other words, they had no entertainment on which to fix their attention. Or take the emergence of the 'quantified self' movement, in which 'life loggers' use smart devices to track thousands of daily movements and behaviours in order to (supposedly) amass self-knowledge. If one adopts such a mindset, data is the only valid input. One's direct, felt experience of the world simply does not compute.

Thankfully, no society has reached this dystopia - yet. But faced with a stream of claims on our attention, and narratives that invite us to treat it as a resource to mine, we need to work to keep our instrumental and exploratory modes of attention in balance. How might we do this?

To begin with, when we talk about attention, we need to defend framing it as an experience, not a mere means or implement to some other end.

Next, we can reflect on how we spend our time. Besides expert advice on 'digital hygiene' (turning off notifications, keeping our phones out of the bedroom, and so on), we can be proactive in making a good amount of time each week for activities that nourish us in an open, receptive, undirected way: taking a stroll, visiting a gallery, listening to a record.

Perhaps most effective of all, though, is simply to return to an embodied, exploratory mode of attention, just for a moment or two, as often as we can throughout the day. Watching our breath, say, with no agenda. In an age of fast-paced technologies and instant hits, that might sound a little ... underwhelming. But there can be beauty and wonder in the unadorned act of 'experiencing'. This might be what Weil had in mind when she said that the correct application of attention can lead us to 'the gateway to eternity ... The infinite in an instant.'

Dan Nixon is a freelance writer whose work has appeared in The Sunday Times, The Economist and The Guardian, among others. He also leads Perspectiva's initiative into the workings of the attention 
economy and is a senior researcher at The Mindfulness Initiative. He lives in London.

\section{REPRINT}

"Attention Is Not a Resource but a Way of Being_Alive to the World" (Dan Nixon, Aeon, December 7, 2018)

OPENLY LICENSED 